\title{
Understanding of Composite Professional Competence Variable of Teacher Students of the Faculty of Technology and Vocational Education
}

\author{
Yadi Mulyadi \\ Electrical Engineering Education Department \\ Faculty of Technology and Vocational Education, Indonesia University of Education \\ Setiabudhi 229, Bandung, West Java , INDONESIA \\ yadi6365@gmail.com
}

\begin{abstract}
It is widely known that the success of teaching and learning systems on TVET is multidimensional, implying that measurement requires a number of different competences to capture each element. The point as an important key of successful at the teaching-learning process in the classroom is teacher professionalism. We need more regulation to combine disparate indicators of teacher professionalism competencies into a single composite measure. This paper will examine the pedagogic, personality, professionalism, and relationship competency's issues that involved in the creation of composite indicators. The analysis suggests that the technical choices which is made in the construction of the composite can have a significant impact on the outcomes. Analytical issue in the design of composite indicators clearly has an important policy implications. This report highlights the issues which need to be connected to the issues about construction of robust composite indicators, so that it can be designed in ways, which will minimize the potential for misleading performance information, also possible to make a failure in deliver the expected improvements or even produce a side-effects.
\end{abstract}

Index Terms - composite variable, professional competence, vocational education.

\section{Introduction}

The new paradigm of improving the quality vocational technology education is through change and innovation of teacher mindset. The teacher as a central agent of change has a strategic role in determining the success of vocational and technology education. The further highlights discussion is about the problems and challenge of teacher (TVET) which require a few responses in terms of skills and competencies that must be updated regularly with the development of technology and relationships with industry [1]. Description above confirms that TVET teachers or vocations are dynamic, progressive and rich in innovation. All systems related to the scope of the teaching profession and vocation interests, ranging from the infra structure, standardization of regulations moving forward samples to perform various maneuvers to face global challenges [2]

The teacher TVET professionals are required to have four competencies as listed in the regulation of the ministry of education and culture [3]-[10]. First pedagogic competence includes: (a) Mastering the characteristics of learners from the physical, social, cultural, emotional and intellectual. (b) Mastering the learning theories and principles of learning that educates.(c) Develop a curriculum related to the subject matter. (d) Conducting educational learning. (e) Carrying out the process of assessment and evaluation of learning outcomes (f) reflective measures for improving the quality of learning

The second competency is competency-related personal characteristics that include personal aspects: (a) Act in accordance with religious norms, legal, social, and cultural. (b) Present yourself as a person who is honest, noble, and become role models for students and the community.(c) Present yourself as a person that is steady, stable, mature, wise and authoritative (d) Shows the work ethic, high level of responsibility, a sense of pride to be a teacher and self-confidence. (e) Upholding the high ethical code of the teaching profession.

The third competence is social competence involves the ability of the teacher as social community residing amid the school environment. Aspects of communal competence consist of.(a) Be inclusive, act more objective, and not discrimination due to consideration of gender, religion, race, physical condition, family background and socio-economic status. (b) Communicate effectively, empathetic and polite to fellow educators, staff, parents and community.(c) Adapting in place served throughout Indonesia, which has a diversity of Indonesia.(d) Communicate with the community's own profession and other professions in oral and written or other forms.

The last competency that must be mastered in a comprehensive qualified teacher is related to the ability of teachers' professional competence in mastering science, technology, or arts and culture at least includes: (a) Mastery subject matter, structures, concepts, and scientific insert, which supported the subject matter. (b) Dominate the standard of competence and basic competence's subject matter. (c) Developing learning materials of teaching creatively. (d) Developing professionalism in a sustainable manner by taking action reflective. (e) Utilizing information and communication technology to develop themselves.

Therefore, in this paper will be measured structural strength, influence prospective teachers' understanding and implementation to the students, which are the students in faculty of Technology and Vocational Education, Indonesia University of Education which has implemented the practice of field experience. The results of the study will show which competencies are the most dominant influences on the performance of the professional teacher. Besides, it will be obtained also how the correlation between the respective competencies. 


\section{Methods}

The analysis models of research conducted in this paper use an SEM by applying the measurement model through confirmatory factor analysis and structural models which performed using regression. " CFA methods of measurement models which reflect observed variables define the construct or latent variable's are not directly measurable but must be inferred. The loading of each observed variable on a factor, indicates its correlation with the construct of interest, and in its commonality with other variables, it identifies the latent variable" [4]. Through the application of SEM measurement model development, researchers can develop an appropriate model to describe the measured data. Confirmatory factor analysis technique is one of the advantages of SEM technique compared with other exploratory factor analysis techniques, because it can modify the model to suit the available data. Besides the reliability estimation process, the right modification model would result in a more accurate estimation by applying the composite reliability coefficient.

Latent variables are variables that cannot be measured directly and need some indicator as a proxy [5]. Observation variables or also called the manifest variable is a variable whose data should be sought through field research, for example, of the survey instruments [6]. Observation variables are used as indicators of latent constructs or latent variables. Moderating variable according to is a variable that has a dependency (contingent effect) a strong relationship with the dependent variable (endogenous) and independent variables (exogenous). The purpose of moderating variables that affect or alter the initial relationship between the independent variables (exogenous) and dependent variable (endogenous)

This study only examines two main competencies which are used as research material that is professional and pedagogical competence. In implementation, two competencies have direct causality relation to the performance of professional vocational teacher. Two competencies are then formulated in terms of the manifest indicator variables. Complete formulations of manifest variables in this study are as follows.

Table 1. Indicator variable manifest [7]- [6]

\begin{tabular}{|c|c|}
\hline Variable & Measure Indicator \\
\hline $\begin{array}{l}\text { Pedagogic } \\
\text { Integrity (Ped.I) }\end{array}$ & $\begin{array}{l}\text { 1. Mastering the characteristics of learners } \\
\text { from the physical aspect, the moral, } \\
\text { spiritual, social, cultural, emotional and } \\
\text { intellectual }\left(\mathrm{X}_{1}\right) \\
\text { 2. Mastering the learning theories and } \\
\text { principles of learning that educates }\left(\mathrm{X}_{2}\right) \\
\text { 3. Develop curriculum related to the subject } \\
\text { matter }\left(\mathrm{X}_{3}\right) \\
\text { 4. Conducting educational learning. }\left(\mathrm{X}_{4}\right) \\
\text { 5. Organizing the process of evaluation and } \\
\text { assessment of learning outcomes }\left(\mathrm{X}_{5}\right) \\
\text { 6. Taking action to improve the quality } \\
\text { reflective learning }\left(\mathrm{X}_{6}\right) \\
\text { 7. Utilizing technology in learning }\left(\mathrm{X}_{7}\right) \\
\text { 8. Communicate effectively }\left(\mathrm{X}_{8}\right)\end{array}$ \\
\hline $\begin{array}{l}\text { Professional } \\
\text { Integrity (Pro.I) }\end{array}$ & $\begin{array}{l}\text { 9. Mastering the substance, structure, } \\
\text { concepts, and scientific mindset that } \\
\text { supports the subject matter }\left(\mathrm{X}_{9}\right) \\
\text { 10. Dominate the standard of competence } \\
\text { and basic competences subject matter } \\
\left(\mathrm{X}_{10}\right) \\
\text { 11. Develop the content of teaching creative }\end{array}$ \\
\hline
\end{tabular}

learning $\left(\mathrm{X}_{11}\right)$

12. Developing professionalism continuously at a reflective action $\left(\mathrm{X}_{12}\right)$

13. Utilizing information and communications technology to develop themselves. $\left(\mathrm{X}_{13}\right)$

Performanace $(\mathrm{P}) \quad$ 14. Working hard inside and outside the classroom $\left(\mathrm{X}_{14}\right)$

15. Have the ability to work individually or in groups $\left(\mathrm{X}_{15}\right)$

16. Having targets measurable achievemen of learning materials $\left(\mathrm{X}_{16}\right)$

17. Being able to create a comprehensive learning plan $\left(\mathrm{X}_{17}\right)$

18. Able to manage the classroom in an orderly manner $\left(\mathrm{X}_{18}\right)$

19. Being able to provide suggestions and ideas to the boss $\left(\mathrm{x}_{19}\right)$

20. Having the ability to perform a comprehensive evaluation $\left(\mathrm{X}_{20}\right)$

21. Guiding academic careers towards higher education $\left(\mathrm{X}_{21}\right)$

The equations model in determining con generic can be expressed in matrix form regression with measurement indicator variable's Xi and composites $s_{\mathrm{i}}$ and element's $\lambda_{\mathrm{xi}}$ as well as the value of the regression coefficient error $\delta_{\mathrm{i}}$ [7][8]. The formulation can be expressed as the following equation :

$$
\mathrm{X}_{\mathrm{i}}=\lambda_{\mathrm{xi}} \varsigma_{\mathrm{i}}+\mathrm{d}_{\mathrm{i}}
$$

$\mathrm{Xi}=$ indicators of exogenous latent variables

$\lambda_{\mathrm{i}}=$ coefficient or factor loading coefficients weighting factor

$\varsigma_{\mathrm{i}}=$ latent variable

$\mathrm{d}_{\mathrm{i}}=$ measurement error

Theoretically, weighting factor coefficient between the indicator will show the manifest variables to the latent variables. Interpreting offensive weights are generally expressed in a standardized form. Implementation standardized factor loadings to evaluate the validity and reliability of each indicator in measuring its latent variables. .... "The square multiple correlations $\mathrm{R} 2$ is also given for each equation. This measure of the strength of the linear relationships. In this context, $\mathrm{R} 2$ is usually interpreted as the reliability of the observed measure " [8]. The complete model of the measurement equation of the three variables can be written:

Table 2. Manifest variable equations measurement model

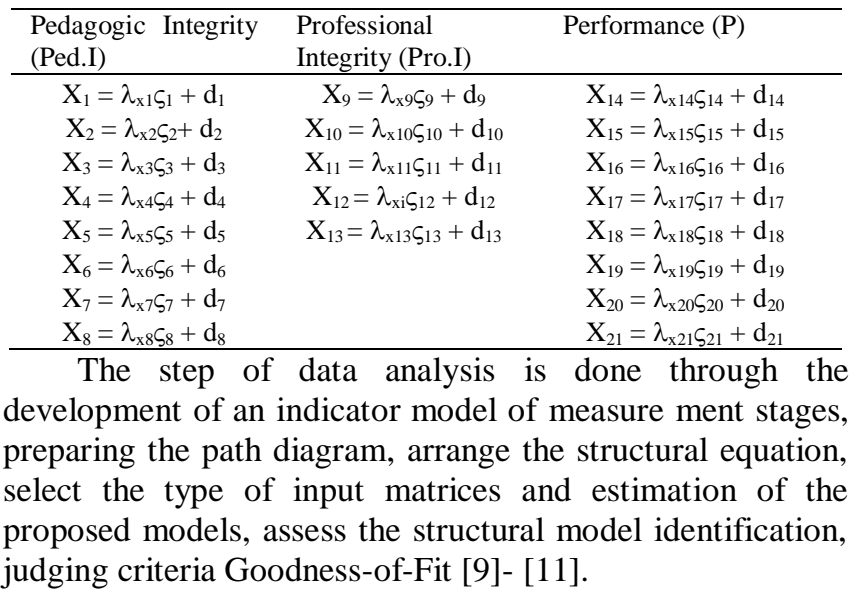




\section{Results and Discussion}

The results of data analysis performed on the partial third latent variable confirmatory factor analysis procedures as a measurement of the dimensions that make up the latent variables in the research model. Latent variables which used in this study consisted of a model of 3-dimensional latent variables in the whole amounted to 21 . Objective of confirmatory factor analysis is to examine multi dimensionality of dimensions forming each latent variable.

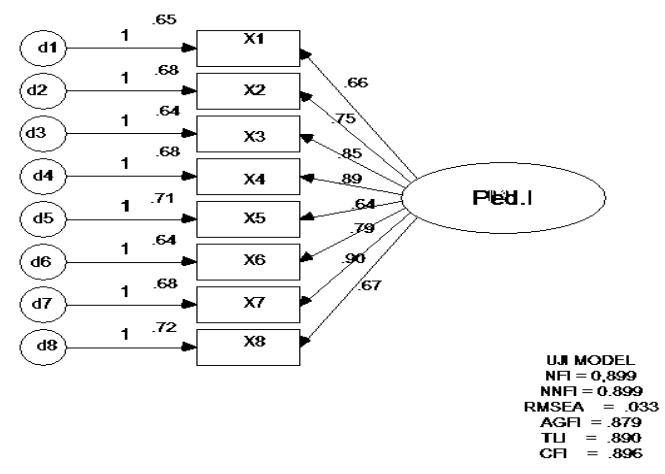

Fig. 1 Confirmatory Factor Analysis result for Ped.I

Data processing used AMOS program, so it can directly obtain information on the reliability of the items on the titled square multiple correlation outputs. In the figure 1 shows that the reliability of the items has a magnitude of at least 0.64 and a maximum of 0.72 . Therefore, it can be said that the grain $\mathrm{X}_{5}$ has a reliability of 0.71 means that the grains can explain the variation of pure variable scores by 71 percent. The existence of the items that have a less than satisfactory reliability in the accuracy of the model, will decrease the value of the model (goodness of fit) as a whole so that if researchers want to get the fit of the model is the high value, this item needs to be excluded in the analysis. In the same way also the CFA conducted on the Pro.I and performance indicators, as well as on his second Ped.I, CFA has met the standard. Overall CFA model analysis performed on all the manifest variables and the obtained results in the following figure:

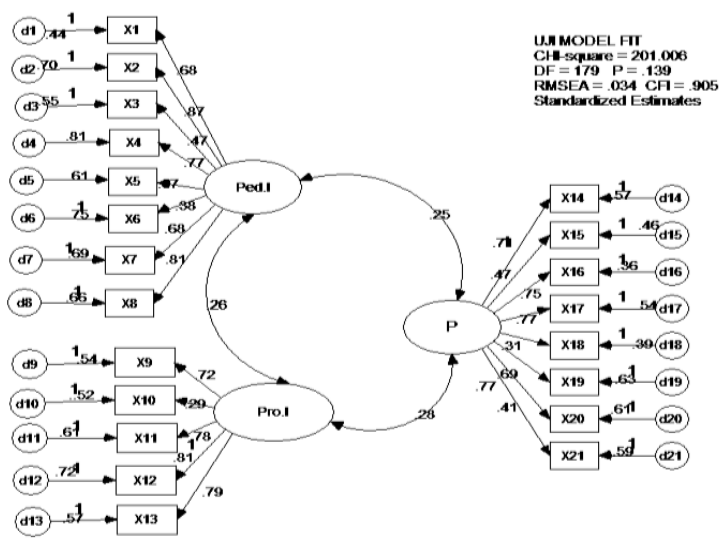

Fig. 2 Overall Measurement Model (SE)

Based on the results in the figure. 2 can be checked that there are some manifest variables that have koefsien weighting factor values less than $0.5 ; \mathrm{X}_{3}, \mathrm{X}_{6}, \mathrm{X}_{10}, \mathrm{X}_{15}, \mathrm{X}_{18}$ and $X_{21}$. These variables are statistically significant but small effect on the latent variables. Therefore, it should be revised analysis of the CFA and the six variables excluded from the model. So the revised CFA analysis model is expected to be more accurate and can represent latent variables. While the weighting coefficient is not significant because the $X_{7}$ factor $P=0.399>0.05$.

After revision by removing the indicator variable weighting factor coefficient of less than 0.5 , then obtained a better result. Teacher performance measurement model fit to the data by the standards of the model test $\mathrm{P}$ value $=0.1120$ $>0.05$; RMSEA $=0.046<0.08$; CFI $=0.99>0.90$. Similarly entirely significant factor weighting coefficient (Pvalue $<0.05)$ with the estimated value of the standardized total $>0,50$. Fourth measurement model (Ped.I, Pro.I and P) provide the estimated value of $\mathrm{CR}>0.78$. Therefore, a conclusion can be drawn that after the revised basis of the proposed measurement model meets the criteria of con generic measurement models. That is, the three latent variables were studied multidimensionality, valid and reliable can be measured by its manifest indicators. Thus the results achieved have indicated Ped.I indicator consists of a composite score of indicator's $\mathrm{X}_{1}, \mathrm{X}_{2}, \mathrm{X}_{4}, \mathrm{X}_{5}, \mathrm{X}_{7}$ and $\mathrm{X}_{8}$. While Pro.I consists of a composite score of indicator variable's $\mathrm{X}_{9}, \mathrm{X}_{11}, \mathrm{X}_{12}$ and $\mathrm{X}_{13}$ as well as indicators of performance indicators include composite score $\mathrm{X}_{14}, \mathrm{X}_{16}$, $\mathrm{X}_{17}$, and $\mathrm{X}_{21}$. Based Ped.I variable data, Pro.I and $\mathrm{P}$ as a composite score of the indicators obtained covariance matrix between indicator variables are as follows:

Table.3 Matriks co-varians

\begin{tabular}{ccccc}
\hline & & & & \\
Rowtype_ & Varname_ & Ped.I & Pro.I & P \\
\hline $\mathrm{n}$ & & 80 & 80 & 80 \\
$\operatorname{cov}$ & Ped.I & .79773 & & \\
$\operatorname{cov}$ & Pro.I & .19976 & .84231 & \\
$\operatorname{cov}$ & P & .20891 & .29541 & .79493 \\
\hline
\end{tabular}

\section{Conclusion}

a. Manifest variables that have a weighting factor coefficient below 0.5 include a composite indicator develop a curriculum related to the subject matter, reflective action to improve the quality of learning, dominate the standard of competence's and basic competences subject matter, have the ability to work individually or in groups, able to manage an orderly classroom, guiding academic careers towards higher education, do not have a big impact in estimating the latent variable performance improvement of vocational teachers.

b. Revised model results show a better path analysis. Test measurement results fit with the data, so that the model is able to estimate the population covariance matrix is not different from the covariance matrix of test samples similarly goodness-of-fit-test (GFT) are eligible statistics chi-square which gives the value of $\mathrm{P} \geq 0.05 ; \mathrm{RMSEA} \leq 0.08$ and or $\mathrm{CFI} \geq 0.90$. 


\section{Acknowledgment}

This paper cannot be completed without the assistance of various parties, both institutionally and individually. First, I say to thank you an appreciation to the chairman of the Electrical Engineering Department of Education has encouraged the author to participate in this International seminar. Then thanks are also extended to the students of the Electrical Engineering Department of Education has to be the respondent. It provides a self-study of this paper. Delivered last thanks to my friends who program doctor vocational technology education has been willing to become an important part in the focus group discussion during this.

\section{References}

[1] Masriam Bukit, Menyiapkan Pendidikan Guru Kejuruan memasuki Standar Internasional, Makalah disampaikan dalam Seminar Internasional, 2008.

[2] Vladimir Gasskov, Managing Vocational Training System, A Handbook for Senior Administrators, 2000.

[3] Permendikbud, Nomor 16 Tahun 2007 Tentang Standar Kualifikasi Akademik dan Kompetensi Guru, 2012.

[4] Schumacker, Randal E. \& Richard G. Lomax, A Beginner's Guideto SEM. New York: Routledge, 2012.

[5] Ghozali, Imam, Model Persamaan Struktural Konsep dan Aplikasi dengan Amos Ver.5. Semarang: BP-UNDIP, 2004.

[6] Hair,Joseph F., Jr., et.al. , Multivariate Data Analysis. Seventh Edition. USA: Prentice-Hall International, Inc. 2010.

[7] Joreskog, K.G. \& Dag Sorbom., LISREL 8: User's Reference Quide. Chicago: Scientific Software International, Inc. 1996.

[8] Raykov, T. Estimation of composite reliability for congeneric measures. Applied Psychological Measurement. 21, ,pp.173-184, 1997.

[9] Raykov, T. Bias of coefficient alpha for congeneric measures with correlated errors. Applied Psychological Measurement, pp69-76, 2001

[10] Undang- Undang Nomor 14 tahun 2005 tentang Guru dan Dosen, 2005

[11]Zinbarg, R. E., Revelle, W., Yovel, I. \& Li, W., . Cronbach's a, Revelle's, b and McDonalds w: Their relations with each other and two alternative conceptualizations of reliability. Psychometrika, 70(1) , 1-11., 2005. 